\title{
Резервы энергетических мощностей: еще одна бездонная бочка
}

Ю.П. ВОРОНОВ, кандидат экономических наук, Институт экономики и организации промышленного производства СО РАН, Новосибирск. E-mail: wrn@online.nsk.su

В статье рассматриваются проблемы резерва энергетических мощностей. Автор приходит к выводу, что эти проблемы требуют решения, прежде всего, в экономическом, а не в техническом контексте: необходимы установление равных прав потребителей и производителей электроэнергии, введение многоуровневой системы страхования объектов электроэнергетики, согласование категорий резервов энергомощностей с международной классификацией.

Ключевые слова: надежность энергосистем, резервы энергетических мощностей, многоуровневое страхование, диспаритет прав, функции ГЭС

В материалах рабочей группы энерготрейдеров я прочитал: «Отрасль “вытащила голову” в сторону развития рыночных отношений, а “ноги оставила” в государственном укладе регулирования стратегии развития». Однако вместо движения в «рыночную сторону» эта отрасль попросту ищет, чем бы поживиться. Эта особенность нашей электроэнергетики проявилась особенно отчетливо, когда потребители стали в явной форме платить за содержание резервных мощностей.

\section{Как определить уровень резервов?}

Под резервами энергосистемы обычно подразумевают резерв генерации, хотя наряду с ним должны быть еще резервы передачи и распределения электроэнергии. Их надежность должна быть одинаковой: неразумно иметь высокие резервы генерации, если линии электропередачи ненадежны.

При определении потребности в резервах в энергетике чаще всего используется показатель «процент от нагрузки», который в разных странах составляет от 10 до 30\% (или 2-10\% от пиковой нагрузки). Либо он должен быть равен мощности максимального источника энергии в системе: если один из источников откажет, то резерв заведомо его компенсирует. 
Единого принципа установления объема резервов в мире нет, поскольку он в той или иной степени определяется рынком. Так, в США действуют разные нормативы на оперативный резерв мощности. Даже в Нью-Йорке они различаются (в восточной части $-3 \%$ от дневной пиковой нагрузки, в южной - не менее 700 мВт). Во Флориде он должен превышать четверть мощности самой мощной электростанции системы, на западе США - 5\% от мощностей ГЭС плюс 7\% от мощностей тепловых станций. При этом есть еще и структурные требования: горячий резерв должен быть не менее половины оперативного ${ }^{1}$.

Кроме того, резервам на тепловых электростанциях должен сопутствовать соответствующий запас топлива, а на ГЭС - воды.

В европейской практике оперативный резерв включает резервы управления трех степеней - первой (доступен в течение 10 секунд), второй (30 секунд), третьей (менее 15 минут), а также медленный резерв диспетчера и аварийный резерв, который, в свою очередь, делится на постоянный, быстрый и медленный. В некоторых странах предусматриваются еще резервы передачи электроэнергии, стабильности, распределения, реактивной мощности и другие [1].

В Евросоюзе сложились разные принципы определения потребности в резервах в разных зонах управления, чаще называемых зонами синхронизации, то есть поддержания стабильной частоты. В континентальной Европе отдельно устанавливаются резервы первой и второй степеней. Потребность в резерве первой степени в Евросоюзе определяется по так называемому «референтному случаю», единому для всей зоны $\mathrm{UCTE}^{2}$ как максимум регулярного (частого) расхождения между генерацией и спросом в зоне синхронизации вследствие непредвиденного падения мощности генерации, нагрузки или разрыва в перетоках электроэнергии. Выбор референтного случая зависит от размеров зоны

\footnotetext{
1 «Горячим» называют тот резерв, который обеспечивается на тепловой станции котлами, уже способными подавать пар на турбины. За рубежом от него отделяют так называемый вращающийся (spinning) резерв, за которым стоят уже вращающиеся генераторы. В российской практике оба резерва объединены, и потому spinning переводится как «горячий». Эти лингвистические различия достойны особого тщательного изучения.

${ }^{2}$ UCTE (Union for the Coordination of Transmission of Electricity) - основанное в 1951 г. энергообъединение 25 европейских стран, синхронные связи с UCTE имеют также Марокко, Алжир, Тунис и западная часть Украины. В 2009 г. преобразовано в ENTSO European Network of Transmission System Operators for Electricity..
} 
синхронизации, мощностей генерации в зоне в целом и самой крупной электростанции, а также соединений с другими зонами.

Резерв второй степени определяется в каждой стране самостоятельно и на уровне ЕС не регулируется. Есть лишь общее представление, что он должен обеспечивать баланс между генерацией и спросом внутри каждой зоны управления с учетом колебаний спроса и непредвиденных аварий. Есть рекомендация (правда, необязательная), что этот резерв должен быть примерно равен мощности самой крупной электростанции. Если зоны распространяются на две или более стран, между ними заключаются соглашения об объемах и территориальном распределении резерва второй степени. Объем резерва третьей степени в континентальной Европе напрямую привязан к резерву второй степени, поскольку должен вводиться после его исчерпания.

Итак, мировой опыт свидетельствует о том, что для определения объемов резерва энергетических мощностей единая методика не используется, отсутствуют и международные стандарты, хотя внутри энергосистем их множество.

\section{Российские особенности}

В РФ принцип, что резерв должен быть «примерно равен мощности самой крупной электростанции», зажил своей отдельной жизнью. В «Методических рекомендациях по проектированию развития энергосистем» баланс мощности считается удовлетворительным, «если дефицит (избыток) (с учетом балансовых перетоков) не превышает половины мощности наиболее крупного агрегата объединения». Обоснований этой цифры не приводится (чем-то это напоминает анекдот о том, как блондинку спросили, какова вероятность, что она, выйдя на улицу, встретит динозавра? На что она ответила: «Пятьдесят на пятьдесят: либо встречу, либо нет»). Но если без шуток, то такой критерий был выбран, скорее всего, потому, что при сложившейся структуре мощностей для его соблюдения можно обойтись минимальными инвестициями.

Это двустороннее движение от норм к реалиям и обратно есть и в других частях тех же рекомендаций. Так, выбор «типов и единичной мощности агрегатов» рекомендуется осуществлять с учетом «влияния повышения единичной мощности энергоблоков на уровень резерва мощности энергосистем» [2. П. 4.7 и 3.5]. 
Между тем еще полвека назад в нашей стране была разработана методика анализа надежности электроэнергетических систем, которая базировалась не на «референтных случаях», а на статистических испытаниях (методе Монте-Карло) [3, 4]. Случайным образом формировались разные состояния, в рамках которых фиксировался дефицит мощности в узлах системы. По результатам многих испытаний рассчитывались математические ожидания дефицита мощности в узлах. Этот подход предполагал, что энергосистема стабильна в широком смысле слова, и это допущение сохранилось и в нынешних рыночных условиях. На его базе строятся оптимизационные экономико-математические модели, в которых минимизируется дефицит мощности, и полученный минимум оптимально распределяется по узлам сети $[5,6]$.

Во времена СССР моделирование касалось незначительной доли мощностей. В плановой системе резервы генерации директивно составляли 4-6\% от нагрузки энергосистемы. При этом считалось, что лимитирующим фактором являются пропускные способности линий электропередач. За последние 25 лет существенные инвестиции в линии не вкладывались, но, когда говорят о резервах мощности, чаще всего, как и в советское время, имеют в виду генерацию, которая больше важна для энергетической компании, чем для потребителя.

По логике, надежность означает соблюдение баланса вырабатываемой и потребляемой мощности в каждый момент времени, т.е. электрические станции, входящие в систему, вырабатывают мощность, равную мощности потребителей и покрывающую потери в сети. В этом заинтересованы все, в том числе потребители. Но обеспечить надежность можно только за счет разных видов резервов. В нашей стране их насчитывается четыре вида, и до последнего времени их объем определялся по отношению к максимальной нагрузке энергосистемы: ремонтный (7-8\%), аварийный (4\%), государственный (1\%) и нагрузочный $(4 \%)$. В сумме получается $16-17 \%$ от максимальной нагрузки.

Смысл первых двух видов мощности понятен из их названия. Государственный резерв предназначен для обеспечения мобилизационных нужд РФ и ликвидации последствий чрезвычайных ситуаций. Нагрузочный (частотный) резерв зависит от режима энергопотребления и нужен для того, чтобы компенсировать нерегулярные превышения нагрузки. 
Считается, что технико-экономические обоснования нужны только для мощностей ремонтного и аварийного резерва. Госрезерв задается государством, а нагрузочный должен определяться в соответствии со статистикой потребления или через рыночные механизмы. В 2017 г. Минэнерго РФ предложило увеличить коэффициент резервирования мощности для конкурентного отбора на 2020 г. до 20,8\% в первой ценовой зоне (европейская часть России, Урал) и до 28,3\% - во второй (Сибирь) $)^{3}$. Предложением учтен вероятный экспортный спрос, который в 2020 г. прогнозируется на уровне 3 гВт. В целом по РФ это обойдется потребителям электроэнергии дополнительно в 5,2 млрд руб. в год [7].

Получается, что за торговлю электроэнергией с другими странами должны платить, прежде всего, сибиряки, поскольку здесь предполагается поддерживать резервы на более высоком (на 7,5 п.п.) уровне, чем в европейской части РФ, а электроэнергия экспортируется именно из восточных регионов страны.

К тому же в Сибири существенно выше доля электроэнергии, получаемой от ГЭС, которые выполняют функции запуска генерирующих мощностей. Аналогичную функцию выполняют для европейской части РФ волжские ГЭС. В связи с этим, в отличие от Европы, зона синхронизации распространяется на существенно большую территорию. Наличие резервов по отдельным блокам регулирования считается ненужным, поэтому их объемы объективно должны быть более высокими. Причем касается это, в первую очередь, резервов по передаче электроэнергии, а не по генерации. Из-за больших масштабов энергосистемы требования к активации резерва - от 3 до 30 минут, что соответствует оперативному резерву третьей категории по европейской классификации.

Ввод в действие резерва производится преимущественно вручную и зависит от квалификации диспетчера. Мощность резерва определяется отдельно для колебаний нагрузки и для возможных аварийных ситуаций. Кроме того, при оценке потребности в резервах учитываются вероятные кратковременные перегрузки генераторов и ЛЭП.

Получается, что в век всеобщей роботизации и автоматизации мы и на перспективу рассчитываем на квалификацию специалистов и на стабильность показателей энергопотребления.

\footnotetext{
${ }^{3}$ Проект Приказа размещен на портале regulation.gov. 5 ЭКО. - 2017. - №9
} 


\section{Надежность и страхование}

Резерв мощности - лишь частный способ обеспечить надежность энергосистем, наряду с качественным оборудованием, регулярными ремонтами, скоростью обеспечения запасными частями и многими другими мерами. Чем хуже налажено все это, тем более значительными должны быть резервы мощности.

Надежность определяется как способность устройства или системы должным образом выполнять свои функции в течение заданного периода и при определенных условиях. Уже из этого определения вытекает необоснованность требования к потребителям платить за резервные мощности, которые призваны повышать надежность энергосистемы. Более оправданной была бы страховая схема, когда оценивается уровень надежности, описываются страховые случаи, и потребителя обязывают приобрести страховку.

До революции 1917 г. Россия лидировала в страховании крупных объектов - в стране были созданы изощренные методики страхования и системы актуарных расчетов. Правда, после революции большая часть специалистов по страхованию эмигрировала, но в это время началась активная деятельность компании «Ингосстрах», которая формально была частной британской, но находилась в 100\%-й собственности Советского государства.

Вообще в плановых хозяйствах вопросы повышения надежности энергосистем решаются проще. Бюджет государств с централизованной экономикой (например, советского или китайского) служит надежным финансовым резервом для страхования крупных энергетических объектов. По этой причине в советское время «Ингосстрах» занимался лишь страхованием высших уровней (то есть тех документов, которые в свою очередь страхуют страховые документы нижнего уровня). Таким страхованием были охвачены почти все крупные ГЭС Латинской Америки. Когда уже в условиях рыночной России произошла авария на СаяноШушенской ГЭС, все с изумлением узнали, что страховка у нее была плоской, одноуровневой, в стиле ОСАГО, будто это не одна из крупнейших ГЭС мира, а подержанные «Жигули».

Поэтому прежде чем решать вопрос о необходимых уровнях резервов энергетических мощностей, нужно навести порядок в страховании крупных энергетических объектов. Действующие сейчас на энергорынке страховые компании, ранее аффилированные с РАО ЕЭС («Энергогарант», «Лидер», «Энергозащита»), 
способны заниматься только одноуровневым страхованием с привлечением к тому же иностранных финансовых средств, тогда как требуется восстановление многоуровневого страхования в энергетике на основе использования прошлого зарубежного опыта «Ингосстраха» применительно к отечественным энергосистемам.

\section{Диспаритет прав}

Сосуществуют два варианта трактовки электроэнергии: как товара и как услуги. После преобразований отечественной энергетики преобладает точка зрения на электроэнергию как единый товар. Поэтому к ее качеству, как и качеству любого товара, могут быть предъявлены претензии. Однако в России этого не происходит по той причине, что не выделены, как это принято в мировой практике, шесть необходимых для доставки электроэнергии до потребителя услуг (распределение, управление и диспетчирование, производство реактивной мощности и регулирование (стабилизация) напряжения, регулирование и стабилизация частоты, симметрирование (обеспечение баланса нагрузки по фазам), поддержание горячего и дополнительного оперативного резервов). В США эти услуги включены в тариф, но если какая-то услуга не выполняется, то поставщик не вправе требовать за нее оплату. У нас же потребление электроэнергии как единого товара избавляет поставщика от претензий. Дескать, купили пирожок и съели его - какие могут быть претензии?

Лишь в ситуации, когда низкое качество потребленной электроэнергии будет законным основанием для отказа платить, станет возможным формирование рынка по каждой из шести связанных между собой услуг. И только рынок в состоянии определить, сколько стоят эти услуги, целесообразно ли самостоятельное исполнение этих функций энергосистемой либо лучше отдать их на аутсорсинг. Главная проблема в том, будут ли эти дополнительные услуги (их список может быть расширен) предоставляться всем, независимо от потребности, или избирательно.

Например, когда резерв генерации исчерпан, а частоту в системе поддерживать не удается, принятые в РФ правила предусматривают отключения «менее ответственных потребителей». Для советской экономики это было естественным. Но в нормальной рыночной экономике разделение потребителей на более и менее 
«ответственных» недопустимо. Это - непозволительное нарушение принципа публичной оферты.

В нашей стране разработка и внедрение рыночных механизмов в целом не завершены даже на рынках зерна и недвижимости. Поэтому нет ничего удивительного в том, что рынки электроэнергии и энергетических мощностей, признаваемые во всем мире наиболее сложными, также далеки от окончательного оформления. Тем более что создание энергетической системы в СССР в условиях плановой экономики сопровождалось экономией во всех сферах, в первую очередь, резервных мощностей. Поэтому единый рынок электроэнергии пока не сложился. Страна разделена на две ценовые зоны: Европу (включая Урал) и Азию. Кроме того, есть еще четыре неценовые зоны (Республика Коми, Архангельская и Калининградская области и Дальний Восток), где цены на электроэнергию не регулируются рынком, и семь изолированных (Сахалин, Камчатка, Чукотка, Якутия, север Красноярского края, Норильск, Магадан), где цены и резервы мощностей регулируются сверху. В неценовых и изолированных зонах применяются методы определения требуемых объемов резервов энергетических мощностей, которые условно можно назвать «внешней оптимизацией».

Существует несколько таких методов. С помощью одного из них минимизируется сумма затрат на резервы и потенциальных потерь у потребителей из-за невысокой надежности системы. При другом добавляется еще один этап, на котором минимизируются затраты на резервы с учетом выявленных на первом этапе оптимальных потребностей в надежности, безопасности и качестве предоставляемых услуг. Наконец, третий метод (частичная оптимизация) перечисленные требования задает изначально. Таким образом, острова плановой экономики продолжают сохраняться в море рыночных отношений.

Поэтому, когда мы говорим о российском рынке электроэнергии и мощностей, нужно иметь в виду, что значительная часть территории РФ из него исключена, а та, что осталась, поделена на две зоны, со своими рынками мощностей.

Комплекс незавершенных рыночных механизмов на рынках электроэнергии и мощностей (разделенных по периодам торговли от почасового до долгосрочного) выглядит следующим образом. Его основу составляет торговля мощностью по регулируемым 
договорам «для населения и приравненных к нему потребителей», определенная не законодательно, а Постановлением Правительства [8]. Практикуются и свободные договоры по мощности и по электроэнергии и мощности при нерегулируемых ценах (они могут быть долгосрочными или разовыми, включать условия относительно технических параметров генерации или обходиться без них). Кроме того, есть торговля мощностью по ценам в рамках конкурсов инвестиций на формирование перспективного технологического резерва мощностей, по мощностям, работающим в вынужденном режиме, для компенсации потерь в сетях и в целях совместных проектов энергетики РФ и иностранных государств и т.д.

Последние три года развивается также торговля мощностью по свободным ценам «путем конкурентного отбора мощности». На нее возлагаются особые надежды, хотя эта конкурсная процедура отбора ценовых заявок на продажу мощности далека от рынка. Так же как в прочих конкурсах, проводимых государством, кроме ценового фактора (стоимости отбираемой мощности), при конкурентном отборе мощности учитываются режимные, технические, территориальные и прочие факторы, включая возможности перетока электроэнергии (в том числе пикового). Фактически конкурентный отбор мощности означает откат от свободного рынка электроэнергии и мощностей в сторону плановой системы, вводимой пока частично.

Причина не только в том, что не модернизировавшаяся четверть века энергосистема страны требует все больше резервов для компенсации снижения надежности оборудования. Принципиальным является сохранение диспаритета прав между производителем и потребителем, поскольку за устранение дефектов энергосистемы можно заставить платить только потребителя.

Карл Маркс в своих размышлениях о России отмечал, что только в этой стране придумали такой прием, как принудительная покупка: «Принудительная продажа в интересах государства существовала у всех цивилизованных наций, но принудительная покупка-русское изобретение» [9. С. 35] (относилось это к принудительному выкупу земли крестьянами при отмене крепостного права). И современный рынок электроэнергии - развитие этого изобретения. Кроме конкурентного отбора мощности, на отечественном рынке есть и «мощность, подлежащая обязательной 
покупке согласно договорам о предоставлении мощности». Это означает, что при покупке киловатт-часов в обязательном порядке приходится оплачивать и «предоставление мощности».

Причем доля этих мощностей неуклонно растет, хотя конкурентный отбор мощности был введен для ограничения принудительных покупок хотя бы там, где они проводятся по явно завышенным ценам. По прогнозам, к 2019 г. генерация по договорам о предоставлении мощности достигнет 36 гВт, то есть увеличится вдвое по сравнению с 2014 г., когда потребителям пришлось заплатить за «предоставление мощностей» 112 млрд руб. А в 2019 г. эта сумма составит уже более четверти триллиона - это примерно $15 \%$ общей выручки генерирующих компаний [10]. Это означает, что рыночные механизмы будут существенно потеснены.

Наведение порядка в рыночной процедуре нерыночными запретами исходно считалось мерой вынужденной и временной. Ожидалось, что в результате конкурентного отбора будут выводиться из эксплуатации неэффективные мощности, но этого не произошло. Ситуация очень похожа на ту, что сложилась с централизованным теплоснабжением на селе и в малых городах. При очередном повышении цены на гигакалорию тепла некоторые потребители отключаются от централизованного теплоснабжения и создают собственный его источник. В результате условно-постоянные расходы делятся на меньшее число потребителей, и тарифы снова приходится повышать. Сейчас по этому пути идут коттеджные поселки, застройщики которых, как правило, выбирают: подключаться ли к «большой» энергосистеме или строить собственную мини-ТЭЦ. Но дойдет очередь и до промышленных предприятий.

Фактически принудительным является и приобретение так называемой мощности, «предоставляемой в вынужденном режиме». Этим термином обозначается мощность наименее конкурентоспособного генерирующего оборудования, которое все же нельзя в данный момент вывести из эксплуатации. «Вынужденность» определяется по одному из двух критериев: источник необходим либо для обеспечения системной надежности электросети, либо для производства. Статусом «вынужденной генерации» отдельные электростанции наделяются раз в три года. Это - классика «ручного управления», когда аргументы в пользу отнесения той или иной электростанции к «вынужденной генерации» сугубо 
индивидуальны, что делает практически невозможным установление одного правила для всех. И тогда начинается коррупциогенная вольница: этому разрешим, а этому нет.

Попытки придерживаться единых правил привели к ряду запретов, в частности на дальнейшее расширение списка объектов вынужденной генерации (в него не включаются объекты, введенные после 2008 г.). Кроме того, пришлось установить ограничения по ценам на мощности, предоставляемые в вынужденном режиме, которые иногда в 30 раз превышали расценки на резервы, получаемые в ходе конкурентного отбора мощности. Сейчас есть надежда, что удастся сократить совокупный объем вынужденной генерации к 2020 г. почти наполовину, до 9,6 гВт. Но все равно это будет в 2,4 раза больше уровня резерва 2012 г,, положившего начало попыткам энергетиков «выбивать» вынужденные резервы генерации.

Возврат к «принудиловке» означает введение дополнительного побора с потребителей, то есть фактически - нового налога. Об этом говорит хотя бы то, что к этому процессу с 2016 г. подключена региональная власть. От губернатора теперь требуется подтверждение о том, что оплачивать вынужденную мощность полностью будут только потребители региона через увеличение тарифов. Он имеет право не выдавать подтверждение, но при этом в любом случае, независимо от того, пройдет ли какаялибо мощность (электростанция, ТЭЦ) конкурентный отбор, она лишится статуса вынужденного резерва. Ее мощность оплачиваться не будет, даже при убыточной работе, в то же время ей запретят приостанавливать поставку тепла (например, если других источников тепла нет). И снова ничего похожего на рыночную экономику.

Сейчас восторги, какими сопровождалось внедрение конкурсного отбора мощности как перспективного рыночного механизма, улетучились. Надежды связываются только с такими договорами на длительные сроки, что еще более удаляет данные процедуры от рыночных. Выяснилось также, что по результатам конкурентного отбора мощности не получается сформировать инвестиционный портфель.

Новые времена - новые надежды. На этот раз они возлагаются на так называемый механизм гарантирования инвестиций, который, как ожидается, будет стимулировать инвестиции, 
модернизацию и реструктуризацию отечественной энергетики. Смысл очередного сочетания плана и рынка на этот раз таков. Заинтересованные федеральные структуры (Минэнерго РФ и другие) составляют долгосрочный инвестиционный план или план развития, вплоть до определения площадок для строительства и сроков ввода генерирующих мощностей. При этом (видимо, еще в рамках техзадания на проектирование) должна учитываться и установленная предельная стоимость каждого проекта. Затем эти инвестиционные площадки разыгрываются в голландском аукционе (то есть с понижением цены до первого покупателя).

Пока механизм гарантирования инвестиций считается наиболее рыночным из доселе применявшихся и самым приемлемым для потребителей. Только мнения потребителей опять никто не спрашивал. При подготовке этого механизма в качестве единственного консультанта выступали те же поставщики.

И в этом случае платить придется потребителю. Чтобы нивелировать последствия от сбоев в работе энергосистемы, необходимо инвестировать в дополнительные мощности. Откуда взять эти инвестиции? Энергетикам кажется естественным, что единственный выход - повышение тарифа, хотя в мировой практике в этом случае используются другие механизмы. Но у нас в стране о рыночной экономике забывают, как только речь заходит о резервах энергетических мощностей, поскольку не исчезла память об относительно недавнем плановом прошлом.

Потребителям приходится покрывать инвестиции в создание этих резервов, а также текущие затраты на их содержание и на ввод их в действие. Правда, тот, кто платит, должен получать имущественные права на то, что он оплатил. Но особенность энергорынка такова, что имущественные права на резервные мощности получает не плательщик, а тот, кому платят. В этом наша страна не одинока. Но за рубежом это отчасти нивелируется ликвидностью резерва энергомощностей, цена которого определяется на рынке.

Цель рынка резервов - не торговать ими, а найти баланс между экономическими выгодами от повышения надежности и необходимыми для этого затратами. Точно такой же смысл и в биржевой торговле, где реальный переход ценностей от одного владельца к другому происходит крайне редко. 
В таком рыночном механизме есть три плюса и три минуса. Во-первых, сохранение и поддержание резервов добавляет услуге ценность вследствие повышения надежности энергосистемы. Во-вторых, резервные мощности можно использовать совместно, что подталкивает к объединению энергосистем. В-третьих, надежность в обмен на издержки всегда ограничивает повышение надежности до какого-то уровня.

Теперь минусы. Во-первых, энергетики не стремятся к удешевлению услуг, поскольку установление цен на основе затрат позволяет оправдать любые затраты, а все издержки перекладываются на потребителей. Во-вторых, оказалось чрезвычайно сложным определить ценность надежности энергосистемы для потребителей, особенно если невозможно показать эффект от этих затрат. И в-третьих, пока не отработаны приемлемые для всех методы оценки мер по повышению надежности. Потребность в резервах определяют на основе опыта эксплуатации, и в ход идут технические, а не экономические аргументы.

Когда потребление превышает генерацию, и действия по восстановлению баланса не предпринимаются, система становится нестабильной: начинаются колебания частоты и напряжения, предваряющие непредсказуемые отдельные отключения или повреждения генераторов и линий и даже полное прекращение работы системы в целом.

Экономические потери потребителей от отключений электроэнергии (издержки отключений) связаны не только с недополученной энергией, но и с неожиданностью каждого отключения. В мировой практике сосуществуют два принципиальных подхода к оценке таких издержек. При одном пытаются напрямую оценить влияние отключений на хозяйственную деятельность или поведение потребителей, при другом - желание потребителей платить за повышение надежности [11]. Но в обоих случаях требуется вычислить функцию ущерба для потребителя от отключений (customer damage function - CDF).

Эта функция зависит от двух параметров: удельного ущерба в расчете на киловатт пикового спроса и продолжительности перерыва. Обычно CDF агрегируется по группам потребителей с учетом топологии сети. А для агрегированной CDF предполагается, что отключения будут распределены по всем потребителям пропорционально нагрузкам. Для первого, более 
распространенного метода, требуются дополнительные допущения, которые касаются преимущественно усредненных оценок. Эти оценки не позволяют ни оценить вероятность аварий и сбоев, ни выработать оптимальную политику их предотвращения. По этой причине в России исчислению CDF не уделяется должного внимания.

Считается, что, помимо оптового рынка электроэнергии и мощности, в нашей стране существует и розничный, участниками которого могут быть и потребители электрической энергии. Но влияние потребителей на цены и объемы резервов мощности нулевое. Потому и участниками рынка они могут быть признаны только условно. Дополнительные услуги, связанные с доставкой электроэнергии потребителю, не дифференцированы. Если даже услуга оказана некачественно, все равно ее приходится оплачивать.

Кстати, если бы потребитель не оплачивал дополнительные услуги, когда их не оказывают, то сибиряки платили бы существенно меньше. По каким причинам? Назову лишь одну из них. В Сибири вторая ценовая зона, и частота электроэнергии за установленные пределы $\pm 0,5$ герц выходит чаще, чем в первой зоне. И такую электроэнергию при нормальном рынке можно было бы не оплачивать.

\section{Резервы энергетических мощностей в контексте других экономических проблем}

Считается, что рынок уравновешивает интересы поставщиков и потребителей энергии. На «невидимую руку рынка» иногда надеются и в отношении размещения резервов. Но на практике рынок мощностей не обеспечивает оптимального территориального их распределения. Производство в последние годы последовательно перемещается в европейскую часть страны, а энергетические мощности остаются на ее востоке. И это не единственный пример того, как проблемы резерва энергетических мощностей вписываются в общеэкономический контекст.

Стоимость резервов и, соответственно, плату за них определить сложнее, чем стоимость киловатт-часа электроэнергии, но эти два процесса связаны следующим образом. Если рынок электроэнергии может быть организован как множество форвардных контрактов, то мощности оплачиваются по спот-ценам (та, по которой продается товар в данное время и в данном месте 
на условиях немедленной поставки). Применительно к электроэнергии «немедленно» означает почасовые продажи электроэнергии на следующий день. Основная цель опционов состоит в уравновешивании прав покупателей и продавцов, поскольку и те, и другие торгуют не товаром, а лишь правами купить или продать. Опцион типа колл предполагает получение права приобрести в будущем какой-либо актив по фиксированной цене, а типа пут - право продажи активов в будущем также по определенной цене. Когда права продать принадлежат кому-то безальтернативно, то владельцы прав купить оказываются в том же положении, что и владельцы денег при товарном дефиците.

Аналогия с колл-опционами позволяет приблизиться к пониманию оценки оперативных резервов. Действительно, продавец резервов определяет цену в зависимости от сложившейся ситуации. Чем чаще отключения, тем выше может быть цена предложения резервов мощности. Чем больше различий в вероятностях подключения, тем больше разрыв в ценах на резервы мощности.

Объемы спроса показывают, сколько готовы платить потребители за резервы генерации и какие выгоды от повышения надежности они могут получить. При дефиците генерирующих мощностей продавец электроэнергии находится в привилегированном положении, имеет возможность диктовать цены как на электроэнергию, так и на резервы мощностей.

Если нет отдельного рынка резервных мощностей, то приходится включать плату за резервы в тариф, причем этот тариф не нулевой даже тогда, когда энергия вообще не потребляется. Для генерирующих компаний это хорошо, поскольку они получают плату при неработающем оборудовании, не расходуя топлива. Но смысл в этом, по мнению многих, все-таки есть. Единый тариф, в котором совмещены оплата потребленных киловатт-часов и плата за резервы, задает определяемые спросом ограничения по цене на то и другое. Это «естественное» ограничение цены позволяет также избежать спекулятивных сделок, вполне возможных на обособленном рынке резервных мощностей. Одна часть такой цены детерминирована, другая носит вероятностный характер.

Трудности вероятностных расчетов и индивидуализация потребностей в энергии не позволяют перейти к качественному страхованию от аварий и отключений. Если потребителям 
полностью компенсировали бы их экономические потери из-за отключений, то страховые платежи и определяли бы величину возможных потерь. Но на практике нигде нет полноценного страхования от отключений электроэнергии. Уже сам этот факт говорит, что это трудно или даже невозможно. Что удивительно, поскольку методы страхования и перестрахования крупных объектов электроэнергетики служат образцом для других отраслей.

При добровольном страховании потребитель может пожелать заплатить за повышение надежности поставок электроэнергии, но путь от его денег до реального снижения риска запутан и не определен. Вместо компенсации за отключения риск снижается за счет увеличения энергосистемы в целом. Но увязать это с величинами страховых платежей сложно, так как многое зависит от индивидуальных характеристик потребителя. Вероятность понести определенный ущерб для малого предприятия - одно, такой же ущерб для крупной компании - другое. Для одной семьи такие платежи - ошибка округления, для другой - финансовый крах.

Получается, что, обсуждая технические вопросы надежности энергосистем, мы выходим на социально-экономические проблемы, далекие от энергетики.

\section{Резервные мощности как тормоз развития}

Резервные мощности в электроэнергетике, по-видимому, сохранятся навечно, но структура их существенно изменится. Основу будущих сетей составят распределенные сети и генерация, а также автоматизированные системы динамической коммутации и контроля надежности энергоснабжения и качества электроэнергии. Многие прогнозируют преобладание комбинированной системы централизованного и децентрализованного снабжения как электроэнергией, так и теплом. Уже в 2014 г. в мире распределенные источники генерации составляли почти половину введенных в эксплуатацию мощностей. До 2023 г. будет построено более 1 тВт распределенной генерации [12]. А в течение ближайших 30 лет централизованные системы будут активно вытесняться распределенными. Новая энергетика будет состоять из разнородных источников электрической и тепловой энергии. Наряду с крупными электростанциями в нее будет включена масса малых предприятий и домохозяйств, продающих в единую 
сеть излишки электроэнергии, вырабатываемой принадлежащими этим домохозяйствам ветряными, солнечными и биогазовыми электроустановками малой мощности.

Правда, этот процесс идет вдали от нашей страны (мой знакомый, давно живущий в Австралии, получает по сотовому телефону СМС-сообщения о том, что автоматика продала в сеть электроэнергию от его солнечных батарей, пока он находился здесь, в Сибири, и на его счет поступили деньги).

При инертности российских энергетических компаний угроза им приходит с неожиданной стороны. С вовлечением в сеть малой и микрогенерации, накопителей и других сетевых устройств энергосистема в большей степени будет напоминать сотовую связь и Интернет, чем привычные нам комплексы электрооборудования. Более того, скорее провайдеры и сотовые компании, чем нынешние энергетические корпорации, будут управлять и владеть энергетикой: для них процедурно ближе требуемые виды работ.

Что касается нашей страны, то по правилам отделенной от реальности «бумажной экономики» в РФ составлена (без предусмотренного финансирования) дорожная карта EnergyNet. Согласно ей энергетический рынок разделен на три сегмента, предполагающих сохранение асимметричных отношений между поставщиками и потребителями электроэнергии. Сегмент «Надежные и гибкие распределительные сети» должен обеспечивать эффективную и надежную работу распределительной сети, способной приспосабливаться к новым объектам и участникам рынка, «Интеллектуальная распределенная энергетика» - интеграцию в энергосистему распределенной генерации, накопителей, средств регулирования нагрузки, а «Потребительские сервисы»индивидуализированные сервисы энергоснабжения и управления инженерной инфраструктурой, в частности, автономными источниками энергии, для конечных потребителей [13]. Но за всеми этими благопожеланиями не стоит реального финансирования и инвестиционных программ.

Магистральный для мировой энергетики путь закрыт для России не потому, что наши ученые не способны придумать ветряк или солнечную панель. Причина - в монополизме поставщика электрической энергии, не допускающего внедрение распределенных источников. 
К 2024 г. по планам-прогнозам доля потребления «зеленой» электроэнергии в России поднимется с $1 \%$ до 4,5-5\%. В мире к 2020 г. эта доля будет равна 12\%, а к 2030 г. - 35\% [14]. То есть в 2024 г. мы будем отставать от мира в четыре раза по этому показателю. А Дания планирует к 2026 г. получать 100\% энергии из возобновляемых источников. В российской энергетике ничего подобного пока не ожидается: ее основой останутся уголь и газ.

Проблемы резервов энергетических мощностей не решаются, на наш взгляд, потому что и экономисты, и технические специалисты-энергетики не считают их своими. Между тем есть все основания утверждать, что эта проблема в большей мере экономическая, чем техническая. Именно из-за отсутствия нормальных экономических институтов и неравноправия участников рынка перспективы развития российской энергетики не внушают оптимизма.

- Оперативный резерв сосредоточился на дорогой энергии ГЭС, а строить новые ГЭС страна не в состоянии. Нужны другие варианты «горячего» резерва.

- Электроэнергия считается товаром, претензии по которому возможно предъявить только постфактум, после его потребления.

- Нет иных источников оплаты создания и содержания резервов, кроме кошелька потребителя, что приводит к повышению инфраструктурных затрат и торможению развития экономики в целом.

- Отсутствует нормальная система страхования энергетических мощностей, нет актуарных расчетов и принятой в мире многоуровневой системы страховок, которые вовлечены в мировой рынок страховых документов.

- Потребителя принуждают к покупке якобы резервов энергетических мощностей, но фактически он не получает никаких имущественных прав на эти резервы.

- Территориальное размещение резервов энергетических мощностей далеко от оптимального, и нет механизмов его улучшения.

- При ориентации на сохранение стабильного гарантированного потребления энергосистемы пытаются максимально переложить на потребителя все риски, хотя совершенно очевидно, что он не способен принять их на себя. Это относится и к государственным гарантиям. 
- Нынешний расклад прав и обязанностей на энергорынке стал причиной того, что путь развития отечественной энергетики отличается от мировых трендов, что предопределяет ее низкую эффективность в будущем.

- Резервы энергетических мощностей из-за неопределенности их необходимых объемов становятся (и частично уже стали) поводом для неконтролируемого повышения тарифов и поборов с населения и реального сектора экономики.

\section{Литература}

1. Allen E.H., Ilic M.D. Reserve markets for power systems reliability // IEEE Transact. Power Syst. - 2000. - Vol. 15. - № 1. - P. 228-233.

2. Методические рекомендации по проектированию развития энергосистем СО 153-34.20.118-2003.

3. Руденко Ю. Н., Чельцов М.Б. Надежность и резервирование в электроэнергетических системах.- Новосибирск: Наука, 1974.

4. Александров И. А., Кузнецов Ю.А., Руденко Ю.Н. Общее и отличительное в исследовании надежности электроэнергетических и газоснабжающих систем // Методические вопросы исследования надежности больших систем энергетики.-1974.- Вып. 1.- С. 6-19.

5. Зоркальцев В. И., Пержабинский С. М. Модели оценки дефицита мощности электроэнергетической системы//Сиб. журн. индустриальной математики.- 2012.- Т. 15.- №1.- С. 34-43.

6. Зоркальцев В. И., Ковалев Г. Ф., Лебедева Л. М. Модели оценки дефицита мощности электроэнергетических систем.- Иркутск: изд. ИСЭМ СО РАН, 2000.

7. Песчинский И. Минэнерго предлагает увеличить резерв мощности//Ведомости.- 2016.- 9 авг.

8. Постановление Правительства РФ от 24.12.2010 № 1107 «О внесении изменений в постановление Правительства Российской Федерации от 24 октября 2003 г. № 643 “О правилах оптового рынка электрической энергии (мощности) переходного периода”».

9. Архив Маркса и Энгельса. т. ХІІ. - М., 1952.

10. URL: www.elec.ru/articles/itogi-regulirovaniya-rynka-moshnosti-2015godu/

11. Billinton R., Allan R., Salvaderi L. (ed). Applied Reliability Assessment in Electric Power Systems//IEEE Press.- New York, 1991.

12. Прогноз компании Global Distributed Generation Deployment Forecast.

13. Материалы Конференции «ИТ-стратегия 2017: новые тренды». 16.02.2017.

14. Данные Wind Energy Association. 